\title{
El relato amoroso en Marianela (1878): UNA EJEMPLIFICACIÓN GALDOSIANA DEL POSITIVISMO COMTIANO
}

\author{
Víctor CANTero García \\ Universidad Pablo de Olavide, Sevilla
}

\section{RESUMEN:}

La presente colaboración trata de evidenciar la apuesta de Benito Pérez Galdós por convertir a Marianela (1878) en un exponente del llamado positivismo comtiano. El análisis del devenir del idilio amoroso entre Pablo, el ciego y Nela, su lazarillo, nos permite descubrir la inclinación de Galdós a favor de las tesis del denominado naturalismo positivista. Un posicionamiento que coincide con el talante progresista y liberal tan propio del temperamento de nuestro autor.

PALABRAS CLAVE:

Galdós, Marianela, positivismo, Comte.

\begin{abstract}
:
The present collaboration tries to demonstrate the attempt by Benito Pérez Galdós to turn his novel Marianela (1878) in an example of the so-called Comtian positivism. The analysis of the development of the amorous relationship between Pablo, the blind man and Nela, his guide, allows us to discover the inclination of Galdós in favor of the thesis of the so-called positivist naturalism. A positioning that coincides with the progressive and liberal attitude so dear the writer's own temperament.
\end{abstract}

\section{KEYWORDS:}

Galdós, Marianela, positivism, Comte.

Cuando J. Casalduero sostiene que: «El lirismo de Marianela es un lirismo ético; refleja la emoción de Galdós ante el fluir de la historia, ante el ritmo de la Humanidad. La alegoría y el símbolo tienen un calor humano, porque traducen los sentimientos de Galdós, expresan su lucha por liberarse de un mundo que le agobia y poderse entregar por entero a la realidad», ${ }^{1}$ nos está dando la clave para analizar las relaciones amorosas entre Pablo, el joven ciego, y Nela, su acompañante, desde la óptica del positivismo. El afán de Galdós por convertir sus novelas en plataformas para fomentar la educación del público lector y su permanente preocupación por

\footnotetext{
${ }^{1}$ Joaquín Casalduero, «Augusto Comte y Marianela», en Vida y obra de Galdós (1843-1920), Madrid, Gredos, 1961, págs. 212-213.
} 
impulsar desde las mismas el progreso y la transformación de España en un país moderno, están muy presentes en la trama argumental de Marianela.

En la presente colaboración nos centramos en el estudio del discurso amoroso protagonizado por dos de los personajes principales de esta novela, en la que, al igual que ocurrirá en Tristana (1892), parecen estar presentes episodios amorosos personales de la vida de Galdós. Así lo testimonia su relación epistolar con Concha Ruth Morell, que coincide en el tiempo con la composición de Tristana, lo mismo que su enamoramiento adolescente de su prima Sisita se deja notar en la redacción de Marianela. Y todo ello porque Galdós estableció claros vínculos entre su vida y la imaginación literaria con la que confeccionó la trama de sus novelas. Vínculos que son relevantes cuando se trata de la importancia ética y la dimensión pedagógica de la literatura; es decir, cuando se considera la función que cumple la literatura en la vida personal. De aquí la importancia de resaltar la capacidad de Galdós para recrear en su imaginación experiencias amorosas vividas y darles forma literaria, pues, a juicio de Julián Marías:

La mayor parte de las relaciones entre personas se viven imaginativamente, se comprenden sin haberlas experimentado, son ellas las que dilatan increíblemente la vida, más allá de los contenidos «reales», forzosamente limitados. Estas vivencias virtuales son el ensayo de la vida compleja, rica y civilizada, y sobre todo el cultivo de la intimidad. ${ }^{2}$

Una de estas posibles recreaciones imaginativas constituye el eje de la trama argumental de Marianela. En esta novela Galdós realiza una detallada descripción del proceso amoroso vivido por Pablo y Nela, a la par que se sirve del mismo para explicitar los principios del naturalismo positivista a los que él se adhiere. Una trama en la que el autor nos presenta al señorito Pablo feliz junto a Marianela, pues debido a su ceguera física, el joven fabula un idilio junto a una joven de extraordinaria belleza, a pesar del limitado concepto que él podía tener de lo bello en su dimensión material. Una dicha que acabará tan pronto el doctor Teodoro Golfín le opere con éxito de cataratas y logre ver. Es entonces cuando su idílica pasión por Nela desaparece al constatar con sus propios ojos la cruda realidad. La fealdad de Nela y la repugnancia que le provoca su cuerpo deforme, desengañan por completo a Pablo, el cual queda al instante cautivado por la belleza de su prima Florentina. En ese choque con la realidad radica la apuesta galdosiana por lo que significa el positivismo comtiano, a saber: el triunfo de la realidad sobre la imaginación. El acierto de Teodoro Golfín al dotar de visión a Pablo implica la victoria de la ciencia sobre la superstición. En otras palabras, la pericia del oftalmólogo es sinónimo del éxito del progreso y de la

\footnotetext{
${ }^{2}$ Marías, Julián, La educación sentimental, Madrid, Alianza Editorial, 1991, pág. 37.
} 
El relato amoroso en Marianela (1878): una ejemplificación galdosiana...

eficacia de los avances científicos que superan el fetichismo, la incultura y el primitivismo de Nela.

Dedicamos el primer apartado de nuestra exposición a describir el romance vivido por los dos jóvenes, entregados por completo a los más variados sentimientos amorosos. Un romance que, en todo momento, es la única razón por la que Nela desea vivir, pues es la causa de su feliz existencia junto a su amo y la fuente que llena su vida de felicidad y contento:

Los negros ojuelos de Nela brillaban de contento, y su cara de avecilla graciosa y vivaracha multiplicaba sus medios de expresión, moviéndose sin cesar. Mirándola, se creía ver un relámpago de reflejos temblorosos, como los que produce la luz sobre la superficie del agua. Aquella débil criatura, en la cual parecía que el alma estaba como prensada y constreñida dentro de un cuerpo miserable, se ensanchaba, se crecía maravillosamente al hallarse sola con su amo y amigo. Junto a él tenía espontaneidad, agudeza, sensibilidad, gracia, donosura, fantasía. Al separarse, creeríase que se cerraban sobre ella las negras puertas de una prisión. ${ }^{3}$

Un enamoramiento que es correspondido por Pablo, el cual en su ceguera se imagina la belleza incomparable de su amada:

-Sí, tú eres la belleza más acabada que puede imaginarse - añadido Pablo con calor - . ¿Cómo podría suceder que tu bondad, tu inocencia, tu candor, tu gracia, tu imaginación, tu alma celestial y cariñosa, que ha sido capaz de alegrar mis tristes días; cómo podría suceder, cómo, que no estuviese representada en la misma hermosura?...Nela, Nela -añadió balbuceante y con afán-. ¿ No es verdad que eres muy bonita? ${ }^{4}$

Sin embargo, esta aventura amorosa tenía los días contados, pues desde su comienzo se establece sobre posturas antagónicas. De una lado, Nela, quien con su imaginación desbordante se mueve en el mundo de la ficción y hace lo posible para que Pablo se la figure como una mujer de una belleza incomparable que nada tiene que ver con la realidad; y de otro, Pablo, quien accede a dicha realidad gracias al acierto de la operación de cataratas que le practica el doctor Golfín. Galdós nos presenta aquí la ficción y la realidad como dos ámbitos irreconciliables, máxime cuando con la primera se pretende ocultar la verdad. Esta contraposición es la que abordamos en el segundo apartado de nuestro trabajo. Y lo hacemos desentrañando

\footnotetext{
${ }^{3}$ Benito Pérez Galdós, Marianela, ed. de Francisco Caudet. Madrid, Cátedra, 6a ed. 2009, págs. 112113. En adelante todas las citas del texto corresponden a esta edición.

${ }^{4}$ Ibíd. pág. 123.
} 
los postulados del positivismo comtiano que están en la base del fracaso de la relación amorosa entre el señorito Pablo y Nela, su guía. El temor de Nela a que su amo la pueda contemplar tal cual es, representa su apego por vivir sumida en la superstición, en el fetichismo y en el engaño; es decir, en el atraso y la incultura, dándole la espalda a la realidad. Por el contrario, el éxito de la ciencia representada por Teodoro Golfín y su pericia como oftalmólogo simbolizan el triunfo de la ciencia sobre la ignorancia, así como el acceso de Pablo al conocimiento de la verdad.

En un tercer apartado tratamos de explicar hasta qué punto la victoria de la ciencia sobre la imaginación y el acceso a la realidad constituye una decidida apuesta de Galdós por los principios del positivismo. Unos presupuestos que están bien presentes en Marianela, pues en esta novela se hacen patentes los tres estados por los cuales, según Comte, ha pasado la Humanidad: el teológico o mundo de los mitos, simbolizado por Nela, el metafísico o mundo de las ideas, representado por Pablo y el positivo o mundo de la ciencia, al que pertenece Teodoro Golfín. Mientras Nela se deja guiar por la imaginación, Pablo se deja conducir -a falta de visión- por el razonamiento. Razonando y discurriendo rectamente tiene que aceptar los hechos que le describe Marianela, pobre niña menesterosa que tan solo vive en su mente. Por su parte, Golfín es la puerta de acceso a la ciencia, gracias a la cual se derrumban los mitos y se deja paso a la verdad.

\section{Un idilio amoroso frenado tras los primeros compases}

Ya Mesonero Romanos en carta a Galdós fechada el 19 de enero de 1879, tras acusar recibo de La familia de León Roch, precisa que en Marianela, Galdós nos ofrece el idilio amoroso entre Pablo y Nela, y se sincera con Galdós confesando que en lo tocante: «al delicado punto de la religión y del culto quisiera no verle a Ud. tan encariñado con este objetivo; más me encanta cuando, prescindiendo de él y ateniéndose solo a la naturaleza como en Marianela, nos regala con un idilio de amor, de sencillez y de ternura». ${ }^{5}$ Por su parte, Menéndez Pelayo dijo de Marianela que era: «el idilio trágico de una mendiga y un ciego, menos original quizá que otras cosas de Pérez Galdós, pero más poético y delicado». ${ }^{6}$ Sobre esta misma cuestión opina Emilia Pardo Bazán, precisando que: «Marianela era un género aparte, puesto que ni de política ni de historia trata; es un drama psicológico, una narración de sentimientos».

\footnotetext{
${ }^{5}$ S. Ortega, Cartas a Galdós, Madrid, Editorial Revista de Occidente, 1964, pág. 30.

${ }^{6}$ Marcelino Menéndez Pelayo, «Don Benito Pérez Galdós», Estudios sobre la prosa del siglo XIX, Madrid, CSIC, 1956, pág. 259.

${ }^{7}$ Emilia Pardo Bazán, «Estudios de literatura contemporánea: Pérez Galdós», Revista Europea, núm. 15, 1880, pág. 412.
} 
El relato amoroso en Marianela (1878): una ejemplificación galdosiana...

Una opinión que es corroborada por Manuel de la Revilla, al señalar que: «si Galdós en otras novelas sabe hacer pensar, en esta ha conseguido hacer sentir, por tan delicado modo que pocos poetas pueden envidiarle». ${ }^{8}$ Concluimos esta serie de testimonios con la opinión de Ricardo Gullón, para quien Marianela es:

Un interludio sentimental. Un retorno a los sentimientos de juventud, al amor llamado a perderse por puro e irreal y adolescente. Marianela, Nela no sólo es una muchacha fea, amada por el ciego y desconocida por el vidente, sino llama de pureza que el viento del recuerdo extrajo de algún rescoldo, de alguna brasa no apagada en el corazón del novelista. En Nela hay mucho de Sisita, la amada juvenil de Galdós, y esa remembranza lejana, hermoseada por la distancia y la adscripción al pasado irreversible proyecta sobre la narración una fragancia. Pues ésta es la novela romántica de Galdós, la compensación por el amor frustrado; el imposible amor, la suprema pureza se incorporaron al orbe ficticio gracias a esta figura ideal. ${ }^{9}$

Todas estas opiniones tienen un elemento común; a saber: que Galdós en Marianela nos muestra su lado más sentimental, recreando en esta novela posibles vivencias amorosas personales, a las cuales da forma en esta obra con especial delicadeza y esmero. $\mathrm{Y}$ es tal su afán por mostrarnos la relación amorosa entre Pablo y Nela como idílica que, tal como precisa Mario E. Ruiz: «Galdós recurre al idealismo platónico para describir a Pablo Penáguilas, como un prototipo directo de claro significado helénico». ${ }^{10}$ Una afirmación que queda corroborada en la siguiente cita:

Salió de casa un joven, estatua del más excelso barro humano, suave, derecho, con la cabeza inmóvil, los ojos clavados y fijos en sus órbitas, como lentes expuestos en un muestrario. Su cara parecía de marfil, contorneada con exquisita figura; mas teniendo su tez la suavidad de la de una doncella, era varonil en gran manera, y no había en sus facciones parte alguna ni rasgo que no tuviese aquella perfección soberana con que fue expresado, hace miles de años, el pensamiento helénico. ${ }^{11}$

Tenemos ante nosotros el arquetipo de la escultura clásica, bien conocido por la armonía corpórea -reflejo de la perfección espiritual- y admirado por la solidez marmórea -reflejo de conocimiento puro-; es decir, que Galdós ha creado a Pablo a

\footnotetext{
${ }^{8}$ Manuel de la Revilla, «Revista crítica», Revista Contemporánea, Tomo XIV, vol. IV, 1878, pág. 509.

${ }^{9}$ Ricardo Gullón, Galdós novelista moderno, Madrid, Gredos, $1^{\text {a }}$ ed., 1973, pág. 73.

${ }^{10}$ Mario E. Ruiz, «El idealismo platónico en Marianela de Galdós», Hispania, vol. 53, núm. 4, 1970, pág. 870.

${ }^{11}$ Benito Pérez Galdós, op. cit., pág. 109.
} 
imagen del Hermes de Praxíteles o del Apolo de Beldevere. El propio Galdós admite esta comparación al encarnar en Pablo a un romano helenizado:

Falto del don que constituye el núcleo de la expresión humana, aquel rostro de Antinoo ciego poseía la fría serenidad del mármol, convertido por el genio y el cincel en estatua, y por la fuerza vital en persona. Un soplo, un rayo de luz, una sensación, bastarían para animar la hermosa piedra, que, teniendo ya todas las galas de la forma, carecía tan solo de la conciencia de su propia belleza, la cual emana de la facultad de conocer la belleza exterior. ${ }^{12}$

Y frente a este dechado de virtudes y de perfección estética, emerge la tímida Nela, incapaz de potenciar, ni tan siquiera de acompañar dignamente las armónicas proporciones de la belleza física de Pablo:

Teodoro se inclinó para verle el rostro. Este era delgado, muy pecoso, todo salpicado de manchitas parduscas. Tenía pequeña la frente, picudilla y no falta de gracia la nariz, negros y vividores los ojos; pero, comúnmente, brillaba en ellos una luz de tristeza. Su cabello, dorado y oscuro, había perdido el hermoso color nativo a causa de la incuria y de su continua exposición al aire, al sol y al polvo. Sus labios apenas se veían de puro chiscos, y siempre estaban sonriendo, mas aquella sonrisa era semejante a la imperceptible de algunos muertos cuando han dejado de vivir pensando en el cielo. La boca de Nela, estéticamente hablando era desabrida, fea. ${ }^{13}$

$\mathrm{Y}$ entre estos dos seres tan distintos en lo físico y lo espiritual surge el amor, de tal manera que, tal como señala Ana María Pérez López:

Vivieron una intensa pasión los días idílicos de juventud, entregados a los efectos de los más variados sentimientos amorosos, la cual se verá truncada por la luz cegadora del sentido estético de Pablo. Éste con Marianela experimentó la alegría íntima y exaltada de una pasión rebosante de libertad, ilusiones (en su caso también de tipo óptico, incluso en el aspecto más literal del término), ternezas, proyectos... júbilo en definitiva, que se revelará al final de la novela, como un ensueño pasajero en la vida del mancebo enamorado. ${ }^{14}$

Merced a este romance idílico Pablo fue feliz junto a Marianela, mientras le duró la ceguera física, pues el joven fabuló un enamoramiento al lado de una muchacha de extraordinaria belleza, a pesar del limitado concepto que él podía tener de lo bello

\footnotetext{
${ }^{12}$ Ibíd.

${ }^{13}$ Ibíd. pág. 88.

${ }^{14}$ Ana María Pérez López, El discurso amoroso en la novela de la Restauración: las novelas de Benito Pérez Galdós, Tesis Doctoral. Universidad de Murcia, 2005, pág.107.
} 
El relato amoroso en Marianela (1878): una ejemplificación galdosiana...

en su dimensión material. Pero es su inmenso deseo de apreciar una excelsa belleza en la figura de Nela -con el natural propósito de que adornase las grandes virtudes espirituales de aquella- lo que le lleva a enamorarse de la joven a través de cuyos ojos se imagina la realidad que no puede ver. Este amor ideal que Pablo y Nela se profesan constituye el nudo gordiano de Marianela, toda vez que, tal como precisa Clarín, se trata de una antinomia que no se resolverá sino con la muerte de la joven:

Fuese o no fuese Marianela ignorante, pagana por ignorancia; fuese o no víctima de la estupidez, del egoísmo, de la impiedad de aquellos empedernidos aldeanos, de todos modos, Marianela, fea, repugnante de figura, pero hermosa en el espíritu, amada por Pablo, ciego, y olvidada por Pablo al volver a la luz, queda como principal objeto de la obra, y la antinomia a que me refería no desaparece..$^{15}$

Y es precisamente Nela quien toma la iniciativa en esta relación, pues pese a sus defectos e imperfecciones reúne las condiciones humanas que se requieren para el enamoramiento, tal como el propio Galdós nos hacer ver:

Nunca se le dio a entender que tenía un alma pronta a dar ricos frutos si la cultivaba con esmero, ni que llevaba en sí, como los demás mortales, ese destello del eterno saber que se nombra inteligencia humana y que de aquel destello podían salir infinitas luces y lumbre bienhechora. Nunca se le dio a entender que, en su pequeñez fenomenal, llevaba en sí el germen de todos los sentimientos nobles y delicados, y que aquellos menudos brotes podían ser flores hermosísimas y lozanas, sin más cultivo que una simple mirada de vez en cuando. ${ }^{16}$

Pablo responde a los requerimientos amorosos de Nela, y tal como precisa Guzmán Álvarez Pérez, a partir de aquí:

Galdós se retira, quedando en su lugar el lenguaje fáctico de dos seres que se aman, pero que no lo expresan [...] mas al poco se va creando un simbolismo claro, contrastado forzosamente, de un lado, por la carencia fisiológica de Pablo, y por la palabra sugerentemente fina de Marianela, por otro..$^{17}$

Las sugerencias e insinuaciones de Nela dan pie a todo un torrente de diálogos amorosos, en los que la ternura y el cariño que se profesan los dos jóvenes son una constante:

\footnotetext{
${ }^{15}$ Leopoldo Alas, Clarín, "Reseña de Marianela", El Solfeo, 13 y 14 de abril de 1878.

${ }^{16}$ Benito Pérez Galdós, op. cit., págs. 102-103.

${ }^{17}$ Guzmán Álvarez Pérez, «Nuevo asedio a Marianela», Actas del III Congreso Internacional Galdosiano, vol. II, Cabildo Insular de Gran Canaria, Las Palmas de Gran Canaria, 1989, pág.11.
} 
Pablo y Marianela salieron al campo, precedidos de Choto, que iba y volvía gozoso [...] ¿A dónde vamos hoy? -repitió el ciego.

- A donde quieras, niño de mi corazón -repuso Nela, comiéndose el dulce y arrojando el papel que lo envolvía-. Pide por esa boca, rey del mundo

[...] Pues yo digo que iremos a donde tú quieras -observó el ciego-. Me gusta obedecerte.

Si te parece bien iremos al bosque que está más allá de Saldeoro. Esto si te parece bien.

Bueno, bueno, iremos al bosque -exclamó Nela, batiendo palmas-. Pero como

no hay prisa, nos sentaremos cuando estemos cansados. ${ }^{18}$

Y momentos más adelante la alegría y el gozo de los enamorados son tan incontenibles que no pueden dejar de expresar lo felices que se sienten:

- ¿Qué sientes cuando estás alegre?

- ¿Cuándo estoy libre, contigo, solos los dos en el campo?

- Sí.

- Pues siento que me nace dentro del pecho, una frescura, una suavidad dulce...

- ¡Ahí te quiero ver! ¡Madre de Dios! Pues ya sabes cómo brilla el sol.

$-¿$ Con frescura?

- No, tonto.

- ¿Pues con qué?

- Con eso.

- Con eso... ¿Y qué es eso?

- Eso - afirmó, nuevamente, la Nela con acento de firma convicción. ${ }^{19}$

Nela trata de explicar a Pablo que «eso» que él siente cuando están solos y que brilla como el sol, no es otra cosa que el cosquilleo del amor que siente por ella. Por medio del lenguaje fáctico se declaran el amor la muchacha menesterosa y el ciego.

\section{El choque de la imaginación con la realidad o los sustratos positivistas de un fracaso amoroso}

Este enamoramiento idílico entre Pablo y Nela se hubiera prolongado sine die, de no ser porque Galdós tenía previsto poner fin al mismo, justo en el momento en el que apareciera el doctor Teodoro Golfín en el establecimiento minero de Socartes. Su llegada marca un antes y un después en el desarrollo de la trama argumental de la novela y determina el desenlace trágico de la misma con la muerte de Nela. La

\footnotetext{
${ }^{18}$ Benito Pérez Galdós, op. cit., págs., 112-113.

${ }^{19}$ Ibíd. págs. 113-114.
} 
El relato amoroso en Marianela (1878): una ejemplificación galdosiana...

aparición de Golfín -que viene a cursar visita a su hermano Carlos, ingeniero jefe de la explotación minera- supone la entrada en escena del elemento que faltaba para convertir a Marianela en una demostración de lo que Galdós entiende por positivismo comtiano, asentado sobre la Ley de los tres estados de la condición humana. Tal demostración comienza en el mismo momento en el que Nela se entera por boca de Pablo de que va a ser operado de cataratas por Golfín. Nela presiente que su suerte está echada, pues al dar rienda suelta a su imaginación, intuye que Pablo logrará ver:

¡Ay, Nela, compañera mía, si fuese verdad, si Dios quisiera tener piedad de mí y me concediese el placer de verte!... Aunque solo durara un día mi vista, aunque volviera a cegar al día siguiente $[\ldots]$

- Sí, lo que tú esperas, será - dijo Nela con aplomo.

- ¿Por qué lo sabes?

- Me lo dice el corazón. ${ }^{20}$

Nela representa el estado teológico, al encarnar en su persona a la imaginación, lo irracional, la superstición:

Habíase formado Marianela en su imaginación poderosa un orden de ideas muy singular, una teogonía extravagante y un modo rarísimo de apreciar las causas y los efectos de las cosas. Exacta era la idea de Teodoro Golfín, al comparar el espíritu de Nela con los pueblos primitivos. Como en éstos, dominaba en ella el sentimiento y la fascinación de lo maravilloso; creía en poderes sobrenaturales, distintos del único y grandioso Dios, y veía en los objetos de la Naturaleza personalidades vagas $[\ldots] .^{21}$

Es decir, Nela vive en el mundo de los mitos, y no acepta la realidad. De aquí que cuando la ciencia -simbolizada en la exitosa intervención quirúrgica mediante la que Golfín le da la vista a Pablo- ella no quiera saber nada al respecto, pues se niega a conocer la realidad. Sabe que una vez que Pablo cuente con la visión se percatará de su fealdad y la rechazará. Se enfrenta a una situación que no está dispuesta a soportar, pues para ella ha terminado su función en este mundo, de aquí que intente suicidarse. La realidad aniquila a la imaginación, la ciencia ha triunfado. Golfín ha dado la vista a los ojos del ciego, ojos con vista que destierran a la imaginación. Este es el final de Nela, la cual muere de tristeza sin saber nadie exactamente cuándo:

\footnotetext{
${ }^{20}$ Ibíd. pág. 128.

${ }^{21}$ Ibíd. pág. 160.
} 
¡Nela! -repitió Pablo, traspasado de dolor y no repuesto del asombro que le había producido la vista de su lazarillo-. Parece que me tienes miedo. ¿Qué te he hecho yo?

La enferma alargó entonces sus manos, tomó las de Florentina y las puso sobre su pecho; tomó después las de Pablo y las puso también sobre su pecho [...] Su respiración fue de pronto fatigosa. Suspiró oprimiendo sobre su pecho con más fuerza las manos de los dos jóvenes. ${ }^{22}$

Y tras este suspiro: «sus labios no se movieron más [...] Teodoro se inclinó y besando la frente de Nela, dijo así con firme acento: - Mujer has hecho bien en dejar este mundo». ${ }^{23}$ Con la muerte de Nela queda superado el primer estado de la Ley comtiana, el cual constituye uno de los tres pilares que, a juicio de J. Casalduero, proporcionan unidad conceptual a Marianela. A ello alude Marie E. Wellington cuando nos precisa que:

En su ensayo -J. Casalduero- describió el simbolismo que encuentra en los personajes principales con respecto a la Ley comtiana de los tres estados de la evolución de la inteligencia humana. Según Casalduero, Nela representa el estado teológico de la imaginación; Pablo el estado metafísico de la razón; y Teodoro el estado positivo de la observación. ${ }^{24}$

El siguiente miembro de esta trilogía es Pablo. En él Galdós representa el segundo estado de la Ley comtiana: la lógica y el razonamiento. Pablo razona y discurre rectamente, aunque no le queda más remedio que aceptar los hechos tal como se los presenta Nela, pobre niña menesterosa que vive en su mente. Su manera de discurrir era por ello tan lógica como disparatada. Partiendo de sus premisas el mundo que se construye es verdadero, pero como no puede observar la realidad por ser ciego, sus ideas carecen de fundamento. Es Golfín quien separa a Pablo de su mundo particular, elaborado según su propia lógica pero que no se atiene a la verdad. Al lograr que Pablo vea le hace vivir en el mundo de la realidad y le aparta del influjo de la imaginación procedente de Nela. Para Galdós, Pablo encarna el estado metafísico que es el producto de la razón arbitraria y destructiva. Se trata de un estado transitorio entre el teológico, que es una construcción arbitraria, pero orgánica de la imaginación, y el positivo o positivista, que se debe a la observación y a la comprobación exacta y orgánica de los fenómenos naturales. De estos tres estados, el primero y el último están completamente definidos, mientras en encarnado por Pablo es más bien interme-

\footnotetext{
${ }^{22}$ Ibíd. págs. 235-236.

${ }^{23}$ Ibíd. pág. 239.

${ }^{24}$ Marie A, Wellington, »Marianela: nuevas dimensiones», Hispania, vol. 51, núm. 1, marzo, 1968 pág. 38.
} 
El relato amoroso en Marianela (1878): una ejemplificación galdosiana...

dio, teniendo como función servir de puente entre los otros dos. Una vez que Pablo cuenta con la visión, Galdós es consciente de que antepone su fe en el progreso «al mundo de ilusión que los dos jóvenes habían creado en su idilio, pues la ciencia, al dar nueva vida a Pablo, destruye a la pobre Nela», tal como precisa Ángel del Río. ${ }^{25}$

Galdós hace suya en Marianela la filosofía comtiana, según la cual:

El hombre comienza por considerar toda suerte de fenómenos como debidos a la directa y continua influencia de agentes sobrenaturales; después los considera como productos de diferentes fuerzas abstractas que residen en los cuerpos y que son distintas y heterogéneas; termina por verlos sometidos a cierto número de leyes naturales e invariables, las cuales son únicamente la expresión de las relaciones observadas en su desarrollo. A la filosofía teológica le preocupa solo desentrañar las causas eficientes de los fenómenos; y a la filosofía positiva, por el contrario, abandonando toda investigación de las causas por inaccesible a la inteligencia humana, le preocupa exclusivamente el descubrimiento de las leyes. ${ }^{26}$

Al contar Pablo con el don de la vista accede a la verdad, pues sus equivocaciones tenían como causa su ceguera. Ahora Pablo deja atrás el canon de belleza que en su mente asumía como el único posible, hecho realidad en la hermosura sin tacha de Nela: «No creas tú, Florentina, que yo no comprendo las bellezas; las siento en mí de tal modo, que casi, casi suplo con mi pensamiento la falta de la vista». ${ }^{27}$

$\mathrm{Y}$ al contemplar la hermosura de su prima Florentina, admite que estaba muy equivocado:

- ¡Oh Dios mío... Esto que veo, ¿es Nela? — dijo Pablo con entusiástica admiración

- Es tu prima Florentina.

- ¡Ah! -exclamó el joven confuso- Es mi prima...Yo no tenía idea de una hermosura semejante. ¡Bendito sea el sentido que permite gozar de esta luz divina! Prima mía, eres como una música deliciosa; eso que veo me parece la expresión más clara de la armonía...28

El tercer protagonista de la citada trilogía es Teodoro Golfín. El doctor encarna al nuevo héroe, al hombre de ciencia, al naturalista. Él es quien representa al estado

\footnotetext{
${ }^{25}$ Ángel del Río, Historia de la literatura española, Edición revisada. New York, Holf, Rinehart and Winston, vol. II, 1963, pág. 38.

${ }^{26}$ J. Casalduero, op . cit. págs. 203-204.

${ }^{27}$ Benito Pérez Galdós, op. cit, pág. 181.

${ }^{28}$ Ibíd. pág. 218.
} 
positivo de la observación. Él simboliza al cristiano ilustrado que busca la verdad, que persigue dar con la realidad. Teodoro como hombre de ciencia emplea el método positivo. Es un hombre que se ha hecho a sí mismo, pues gracias a su voluntad y esfuerzo venció en la lucha por la existencia. Es una excelente persona. Como oftalmólogo vive entregado al conocimiento de la ciencia que practica. Galdós nos lo describe como un profesional que se dedica con pasión a la medicina:

No dejaba de manifestar a cada momento la estimación en que a sí mismo se tenía. Pero la vanidad de aquel hombre era la más discutible de todas las vanidades, pues consistía en sacar a relucir dos títulos de gloria, a saber: su pasión por la Cirugía y la humildad de su origen. ${ }^{29}$

Teodoro simboliza al hombre que busca la realidad para salir del caos intelectual, producto del primitivismo y de la superstición. En él se hace patente la eficacia del progreso, él encarna el tránsito de la oscuridad y de la ignorancia, a la luz y la verdad. Teodoro, a juicio de Francisco Caudet:

Hace un doble papel en Marianela: ejercer su profesión de médico, devolviéndole la vista a Pablo, y adentrándose, como hace un minero en la mina, en el laberinto interior de Nela, donde moran las piedras preciosas. Eso es lo que es Nela: una piedra preciosa que todo el mundo, salvo Teodoro y Pablo mientras es ciego, desdeña. ${ }^{30}$

Estos son los elementos sustanciales del simbolismo que se contienen en Nela, Pablo y Teodoro. El hecho de que Galdós nos presente a estos tres personajes coexistiendo en Socartes es una clara señal de su propósito de novelar la evolución de la Humanidad, a medida que esta va pasando de uno a otro de los tres estados comtianos.

\section{El triunfo de la apuesta de Galdós por el naturalismo positivista}

Tal como precisa J. Casalduero, Galdós: «con Marianela supera el trabajo realizado y se abre camino por la obra a realizar, en la cual la realidad, la ciencia y el trabajo estarán en conflicto continuo con la imaginación y el ocioso soñar; el presente histórico luchando perpetuamente con el pasado histórico». ${ }^{31}$ Un conflicto que está en la base del naturalismo positivista, el cual Galdós nos presenta por primera vez

\footnotetext{
${ }^{29}$ Ibíd. pág. 137.

${ }^{30}$ Francisco Caudet, «Introducción», Marianela, Madrid, Cátedra, 2009, pág. 29.

${ }^{31}$ Joaquín Casalduero, «Introducción», Marianela, Madrid, Cátedra, 1993, pág. 43.
} 
El relato amoroso en Marianela (1878): una ejemplificación galdosiana...

en esta novela, tal como afirma Jacques Beyrie: «certaines pages de Marianela font songer au ton et à la technique des romanciers dits "naturalistes"». ${ }^{32}$ Un acercamiento de Galdós a los principios del naturalismo sobre el que incide J. F. Montesinos al señalar que:

El lugar donde los yacimientos mineros se encuentran, las explotaciones mismas y el carácter de esa explotación, todo ha hecho que el autor ponga más atención en los ambientes que nunca antes. Las descripciones del terreno son detallistas como nunca antes [...] Todo esto nos parece ya franco naturalismo. Y nos recuerda los procedimientos de esta escuela el gran caudal de tecnicismos de minería que a lo largo del libro encontramos, como nos lo recuerda Golfín, que habla como médico aún a los que no lo entienden, ni muchos lectores se harán cargo de qué es eso de «capas corticales», «examen catóptrico». Todo eso anuncia un pronto advenimiento del naturalismo. ${ }^{33}$

Resulta claro, por tanto, que en Marianela Galdós adopta el enfoque de la novela naturalista, lo cual no supone una ruptura con el canon estético que sigue en sus novelas de tesis, pues tanto en éstas como en Marianela existe un muestrario de rasgos naturalistas. De hecho, los conflictos planteados en Dña. Perfecta, Gloria o La familia de León Roch, siendo de naturaleza distinta, tienen en común con Marianela el hecho de fundamentarse en una antinomia o contradicción como principal objeto de la obra. En otras palabras, Marianela no es un paréntesis en la producción novelística de Galdós para acallar las voces de la memoria y la mala conciencia por el posible lance amoroso que nuestro autor mantuviera con su prima Sisita. Al contrario, esta novela es una pieza perfectamente ubicada en el universo narrativo, que novela a novela Galdós, positivista de formación y de temperamento, había empezado a construir. Un universo en el que Galdós coincide con otras novelas posteriores representativas del naturalismo social, como Germinal (1885), de Zola. Entre Marianela y Germinal existe un claro paralelismo. Si bien es cierto que Teodoro es un médico afamado, mientras que Étienne Lantier es un obrero en paro, los dos están perdidos al comienzo de ambas novelas, en una noche oscura; y los dos descubren, en términos parecidos, el paisaje geográfico y humano de la mina.

En cierta medida podemos afirmar que Galdós se sirve del idilio amoroso entre Pablo y Nela para hacer patentes los postulados del naturalismo positivista que él asume como propios tras leer a Comte. Y lo afirmamos porque uno de los propósitos filantrópicos de Galdós al redactar sus novelas es lograr la reconciliación del lector con la realidad material que le ha tocado vivir, sin renunciar por ello a la dimensión

\footnotetext{
${ }^{32}$ Jacques Beyrie, Galdós et son mithe, II, Lille, Univesité de Lille III, 1980, pág. 287.

${ }^{33}$ J. F. Montesinos, Galdós, I, Madrid, Castalia, 1968, págs. 242-243.
} 
espiritual de su existencia. De aquí que cuando el lector se percata del miserable final de personajes galdosianos como Isidora Rufete, Alejandro Miquis o Marianela aprecie con más intensidad su deseo de vivir apegado a la realidad, se libere de los temores a lo desconocido y se aplique a descubrir por medio de la ciencia, la razón y la lógica los secretos que se encierran en los fenómenos naturales. Esta es la actitud de Pablo, su amor hacia lo que le rodea, su conocimiento metafísico y espacial -no visual- del mundo y su decidido positivismo son sus señas de identidad. Una actitud que se hace patente en el mismo momento en el que Teodoro Golfín le otorga el don de la vista. En ese momento Pablo reclama los placeres de la belleza formal y rechaza el supuesto amor que sentía por Marianela, que en modo alguno puede competir con la belleza de Florentina. Un rechazo que Nela presumía, pues en todo momento se opuso a describirse físicamente por más que Pablo se lo pidiera. De aquí que, tal como señala Gonzalo Sobejano, al final del Capítulo VI:

Todo el júbilo de los enamorados parece estar a punto de extinguirse, cuando Pablo pregunta a su amiga: «-Dime, Nela, ¿cómo eres tú? La Nela no dijo nada. Había recibido una puñalada». Estas son las últimas palabras del capítulo y aunque los dos siguientes se titulen «Más tonterías» $\mathrm{y}$ «Prosiguen las tonterías», el entusiasmo de aquel que iniciaba la escena ya no alienta en la misma medida. ${ }^{34}$

Un rechazo que, en todo caso, está justificado, pues Pablo ciego percibe la belleza espiritual de Nela, pero al contar con la visión se percata de la realidad material física observable.

\section{A modo de conclusión}

Es posible que en Marianela Galdós reviviera alguna de sus experiencias amorosas e hiciera suyo un principio que G. K. Chesterton establece en su obra La ficción como alimento, en el sentido de que la realidad, lo vivido puede alimentar la ficción: «toda persona sana ha de alimentarse tanto de la ficción como de la realidad en algún momento de su vida; porque la realidad es una cosa que el mundo le da, mientras que la ficción es algo que ella da al mundo». ${ }^{35}$ Una circunstancia a la que también alude Manuel Herrera Hernández, al señalar que: «Todo novelista parte al escribir, de un modo consciente o inconsciente, de su propia vida y de su intimidad. En Be-

\footnotetext{
${ }^{34}$ Gonzalo Sobejano, "Galdós y el vocabulario de los amantes”, Anales Galdosianos, Año I, 1966, pág. 88.

${ }^{35} \mathrm{G}$. K. Chesterton, El amor o la fuerza del sino, trad. de Álvaro de Silva, Madrid, Ediciones Rialp, 2000, pág. 120.
} 
El relato amoroso en Marianela (1878): una ejemplificación galdosiana...

nito Pérez Galdós la vida íntima queda oculta por sucesos imaginarios unos y otros ciertos que nos impiden descubrirla. Por esto pensamos que en muchas de las obras de Galdós su presencia está oculta en el anonimato de algún personaje». ${ }^{36}$

Sin embargo, Marianela no es solo la expresión artística de sus ideas, sino su credo estético. Gracias a ella puede liberarse del periodo abstracto a que le había conducido su estudio de la formación de la sociedad contemporánea en España y dedicarse por completo a la observación de su época y a la descripción de la realidad. En este sentido podemos afirmar que Marianela es el manifiesto del naturalismo en España, desde el punto de vista ideológico y estético. Esta apuesta de Galdós por transformar el idilio amoroso entre Pablo y Nela en la representación del triunfo de la realidad sobre la imaginación es lo que hemos pretendido demostrar en la presente exposición. Este triunfo subraya el interés de Galdós por traer a colación en Marianela su preocupación por la realidad social de la España en la que vive.

Galdós hace explícita en Marianela su profesión de fe en pro del progreso de la Humanidad por medio de la ciencia y el trabajo. Deja a un lado las puras abstracciones a las que le había conducido su estudio histórico de España y se entrega con agrado al análisis de la realidad captada por los sentidos. En otras palabras, en esta novela su autor nos deja claro un mensaje: la ignorancia y la superstición tienen que desaparecer, pues el ser humano tiene que lograr la mejor comprensión posible de los fenómenos naturales con el auxilio de la ciencia y el respaldo de su dedicación y trabajo.

\section{Referencias bibliográficas}

Alas, Leopoldo, Clarín, El Solfeo, 13 y 14 de abril de 1878.

Álvarez Pérez, Guzmán, «Nuevo asedio a Marianela», Actas del III Congreso Internacional Galdosiano, vol. II, Las Palmas de Gran Canaria, Cabildo Insular de Gran Canaria. 1989, págs. 8-18.

Beyrie, Jacques, Galdós et son mithe, vol II, Lille, Université de Lille III, 1980.

Casalduero Joaquín, "Augusto Comte y Marianela", Vida y obra de Galdós, (1843-1920), Madrid, Gredos, 1960.

Casalduero, Joaquín, Introducción», Marianela, Madrid, Cátedra, 1993.

Caudet, Francisco, «Introducción», Marianela, Madrid, Cátedra, 6 ${ }^{a}$. Ed, 2009.

Gullón, Ricardo, Galdós novelista moderno, Madrid, Gredos, 1960.

Marías, Julián, La educación sentimental, Madrid, Alianza Editorial, 1993.

\footnotetext{
${ }^{36}$ Manuel Herrera Hernández, «Amores, amoríos y rumores en la vida de Galdós», Isidora: Revista de Estudios Galdosianos, 9, 2009, pág. 65.
} 
Menéndez Pelayo, Marcelino, "Don Benito Pérez Galdós", Estudios sobre la prosa del siglo XIX, Madrid, CSIC, 1956.

Montesinos, J. F., Galdós, I, Madrid, Cátedra, 1968.

Ortega, S., Cartas a Galdós, Madrid, Editorial Revista de Occidente, 1964.

Pardo Bazán, Emilia, «Estudios de literatura contemporánea: Pérez Galdós «, Revista Europea, 15, 1880, págs. 347-413.

Pérez Galdós, Benito, Marianela, Madrid, Cátedra, 2009.

Pérez López, Ana María, El discurso amoroso en la novela de la Restauración: las novelas de Benito Pérez Galdós, Murcia. Universidad de Murcia, 2005.

Ruiz, Mario E., «El idealismo platónico en Marianela, de Galdós», Hispania, vol. 53, núm. 4, 1970, págs. 870-880.

Sobejano, Gonzalo, «Galdós y el vocabulario de los amantes», Anales Galdosianos, Año, I, 1966, págs. 85-89.

Wellington, Marie E., «Marianela: nuevas dimensiones», Hispania, vol. 51, 1968, págs. 38-48. 